\title{
Elevation of Urinary Trehalase and Maltase Activities with Maturity-Onset Diabetes Mellitus
}

\author{
Masatoshi NaKano, ${ }^{1, *}$ Akihisa IguchI,${ }^{2}$ Hidehiko Kurimoto, ${ }^{2}$ \\ and Nobuo SAKAMOTO ${ }^{2}$ \\ ${ }^{1}$ Institute for Medical Science of Aging, Aichi Medical College, \\ Nagakute, Aichi 480-11, Japan \\ ${ }^{2}$ The Third Department of Internal Medicine, Nagoya University, School of Medicine, \\ Nagoya 466, Japan
}

(Received February 18, 1987)

\begin{abstract}
Summary In the case of maturity-onset diabetes mellitus, urinary trehalase and urinary maltase activities were significantly elevated as compared with those of healthy individuals. The urinary trehalase activity in non glucosuric and non proteinuric patients was higher than that in healthy individuals, and the trehalase activity in those diabetics with proteinuria was significantly higher than in those without it $(p<0.05)$. Both urinary trehalase and maltase activities were elevated with increased concentration of urinary $\beta_{2}$-microglobulin in this diabetics. Furthermore, urinary trehalase was elevated in disease of short duration (1-4 years), whereas in that of relatively long duration (more than 13 years) the activity was rather low. These results suggest that renal brush borders are damaged in the early stages of the disease and that urinary trehalase is a good indicator of renal tubular damage.
\end{abstract}

Key Words: urinary trehalase, urinary maltase diabets mellitus, renal tubules, renal brush borders

With any disease it is important to detect the disorder as early as possible. In diabetes mellitus, proteinuria, an important parameter used to measure renal function, is also a clinical sign of diabetic nephropathy. However, the diabetic kidney is known to undergo many functional and morphological changes in the early stages of disease prior to the appearance of clinical nephropathy $[1,2]$.

Parving et al. [3], focusing on tubular proteinuria [4] in diabetes mellitus, measured the renal excretion of $\beta_{2}$-microglobulin. In healthy persons, the small molecular weight protein $\beta_{2}$-microglobulin is freely filtered through the glomerulus and

\footnotetext{
* To whom correspondence should be addressed.
} 
completely reabsorbed at a tubular site [5].

It is well known that in $\mathrm{HgCl}_{2}$-induced nephrotoxicity damage to tubular brush borders occurs [6]. In this case the brush border enzymes maltase, LAP and $\gamma$-GTP are excreted in the urine [7-9]. Recently we reported that urinary trehalase activity is elevated in $\mathrm{HgCl}_{2}$-induced nephrotoxicity [10], and in chronic toxicity due to prolonged exposure to low levels of cadmium [11]. The enzyme trehalase [E.C. 3.2.1.28] splits trehalose ( $\alpha$-D-glucopyranosyl- $\alpha$-D-glucopyranoside) to two glucose moieties. It has been proved by biochemical [12-14] and immunohistochemical procedures [15] that renal trehalase is localized in the brush borders of proximal tubules. Of the brush border enzymes, maltase, leucine aminopeptidase (LAP), and $\gamma$-glutamyl transpeptidase $(\gamma$-GTP) are solubilized by papain, but not trehalase [14]. Thus, it is suggested that trehalase has a different localization in the membranes from other brush border enzymes such as maltase, LAP, and $\gamma$-GTP [16]. Urinary trehalase shows the same antigenicity as renal trehalase. It has been proved biochemically and immunohistochemically that the trehalase content in kidney tubules is significantly decreased in acute tubular necrosis [10] and in the case of chronic cadmium poisoning [11]. More recently, we reported that inhabitants of cadmium-polluted areas [17] and patients with Itai-itai disease [18] show renal tubular damage. In fact, the renal tubular damage seen in Itai-itai disease is extremely severe [19]. Higuchi et al. [20] reported that normal pregnant women showed an elevation of urinary trehalase activity and that after delivery the activity was quickly restored to the level of healthy individuals, suggesting repair of the renal tubular damage.

This paper deals with the elevation of urinary trehalase and urinary maltase activities in patients with maturity-onset diabetes, and with the relationship between urinary enzymes and such factors as urinary sugars, urinary protein, $\beta_{2}$ microglobulin, and duration of disease.

\section{EXPERIMENTAL PROCEDURES}

Urine collection. (a) Pathological subjects: Twenty-four-hours or two-hours morning urine $(7: 00-9: 00)$ specimens were collected from patients with diabetes mellitus (maturity onset type), who were admitted to Nagoya University Hospital. The 24-h urine specimens were collected into glass bottles without preservative, and the urine was kept at $4^{\circ} \mathrm{C}$ during the collection period. (b) Normal subjects: We studied 200 clinically healthy individuals for normal specimens of the 2-h morning urine. Only experimental data from subjects who had normal results of urinalysis were selected for the estimation of normal limits. Thus, 32 subjects were excluded for the reason just stated above. The remaining sample consisted of 87 men (mean age, 48 years; range, 29-68 years) and 81 women (mean age, 45 years; range, 25-68 years).

Pretreatment of urine. Five milliliter of the urine was dialyzed thoroughly against distilled water as described previously [10]. The dialyzed urine was then 
concentrated 10-fold (to $0.5 \mathrm{ml}$ ) with a Minicon B-15 (Amicon Co.), and this concentrate was used as the enzyme solution.

Assay for enzyme activity. Trehalase activity was determined by the method described previously [21, 22]. The reaction mixture contained enzyme solution, $40 \mu \mathrm{mol}$ of trehalose, and $20 \mu \mathrm{mol}$ of phosphate buffer ( $\mathrm{pH} \mathrm{6.2)}$, in a total volume of $0.25 \mathrm{ml}$. After incubation at $37^{\circ} \mathrm{C}$ for $60 \mathrm{~min}$, the reaction was stopped by addition of the Tris-glucose oxidase-peroxidase reagent of Dahlqvist [23] which was used for the determination of the liberated glucose. Maltase activity was assayed similarly with maltose as the substrate. The activity of trehalase and maltase was expressed as $\mu \mathrm{mol}$ glucose formed per $\mathrm{h}$ per $\mathrm{g}$ creatinine.

Analytical procedures. Sugar and protein contents in the urine were determined by automated methods. Urinary creatinine content was determined by the Jaffe method. Urinary $\beta_{2}$-microglobulin was assayed with an enzyme immunoassay KIT (FUJIREBIO Co., Tokyo) based on an enzyme-immunoassay method [24]. There were no urine specimens below $\mathrm{pH} 5.5$ in which $\beta_{2}$-microglobulin was measured.

Statistics. Differences between means were tested by Student's $t$-test. Relationships between variables were tested with linear regression lines and correlation coefficients.

\section{RESULTS}

Trehalase is quite stable in urine, and no significant loss of activity was observed during storage at $4^{\circ} \mathrm{C}$ or at $-80^{\circ} \mathrm{C}$ for at least 2 weeks. Satisfactory reproducibility was obtained with sample from both healthy and pathological individuals.

As can be seen in Fig. 1, trehalase activity in the 24-h urine showed a good correlation with that in the 2 -h morning urine. Similar results were obtained in the activity of urinary maltase (data not shown). Thus, we employed the 2-h morning urine specimens in the following experiments.

As shown in Table 1, both urinary trehalase and maltase activities were significantly higher in diabetes mellitus patients than in healthy controls $(p<0.01)$. No significant difference, however, was observed in urinary trehalase activity between male and female patients with diabetes mellitus: male $(n=36), 14.3 \pm$ 1.35 ; female $(n=43), 15.2 \pm 1.42$. Nor were there any age-related differences (data not shown). Urinary maltase activity in the diabetics also was not sex- or agerelated (data not shown).

As shown in Fig. 2, trehalase activity in the diabetic group without glucosuria $(n=20)$ and in that with glucosuria $(n=38)$ was $11.3 \pm 2.41$ and $19.4 \pm 2.94$, respectively, but the difference was not significant. However, both groups were observed to have significantly higher trehalase activity than that of healthy individuals $(p<0.01)$. On the other hand, trehalase activity in the diabetics without proteinuria $(n=27)$ and in those with proteinuria $(n=31)$ was $11.9 \pm 2.17$ and $21.3 \pm$

Vol. 3, No. 2, 1987 


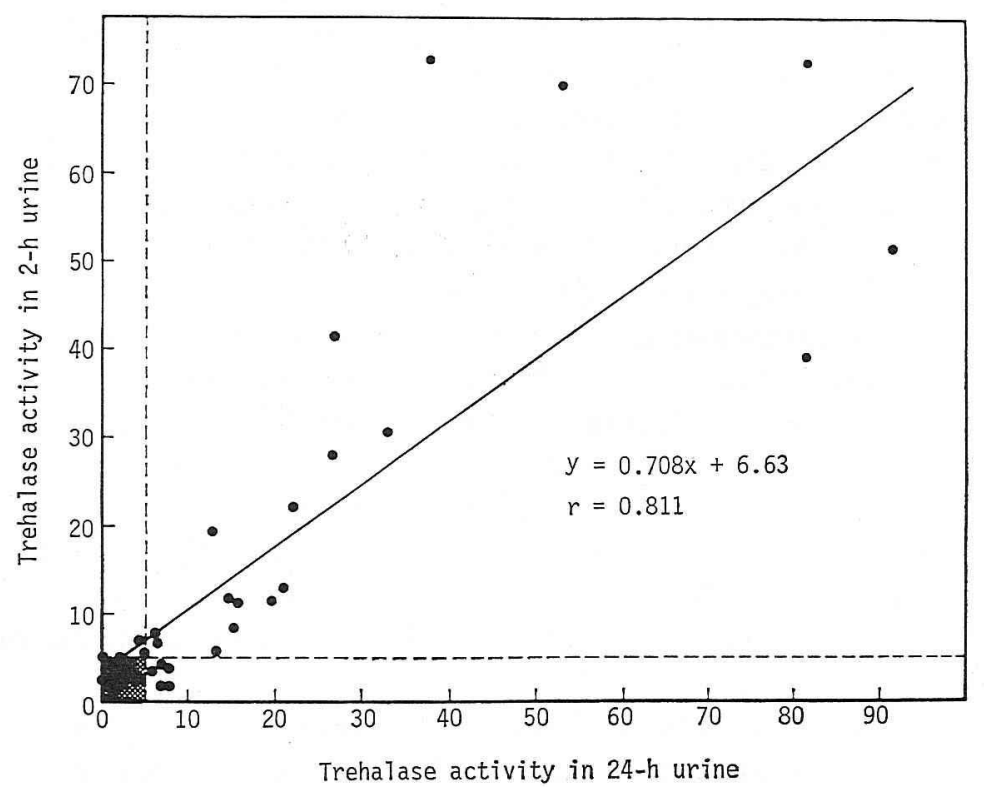

Fig. 1. Correlation between trehalase activity in 24-h urine and that in 2-h morning urine. The 2-h morning urine was collected from 7 a.m. to 9 a.m. Urine specimens were collected from 40 patients (mean age, 52 years; range, 30-78 years).

Table 1. Urinary trehalase and maltase activities in diabetes mellitus.

\begin{tabular}{lcl}
\hline & Trehalase & Maltase \\
\hline Control $(n=168)$ & $2.89 \pm 0.25$ & $163 \pm 11.0$ \\
Diabetes mellitus $(n=82)$ & $11.14 \pm 1.19^{*}$ & $269 \pm 20.7^{*}$ \\
\hline
\end{tabular}

*Significant difference, $p<0.01$.

3.29, respectively, and this difference was significant $(p<0.05)$. The trehalase activity in urine of diabetics with neither glucosuria nor proteinuria was significantly higher than that in urine specimens from healthy individuals $(p<0.01)$.

As shown in Fig. 3, urinary trehalase activity in the diabetics showing more than $200 \mu \mathrm{g} /$ liter of $\beta_{2}$-microglobulin was significantly higher than that in the healthy group. Significant difference was observed in the group with a lower level of $\beta_{2}$-microglobulin ( $0-200 \mu \mathrm{g} /$ liter). In the case of urinary maltase (Fig. 4$)$, the activity in all three groups of patients $(0-200,200-1,000$, and more than 1,000 $\mu \mathrm{g} /$ liter of $\beta_{2}$-microglobulin) was also significantly higher than that in the healthy group.

As shown in Fig. 5, the plotting of urinary trehalase activity against the duration of disease yielded a parabolic curve. The activity in the 5-8 year group was the highest seen in any other group. No significant difference was observed between normals and patients having the disease for less than one year. Those patients with the disease of long duration (more than 13 years) showed relatively low urinary 


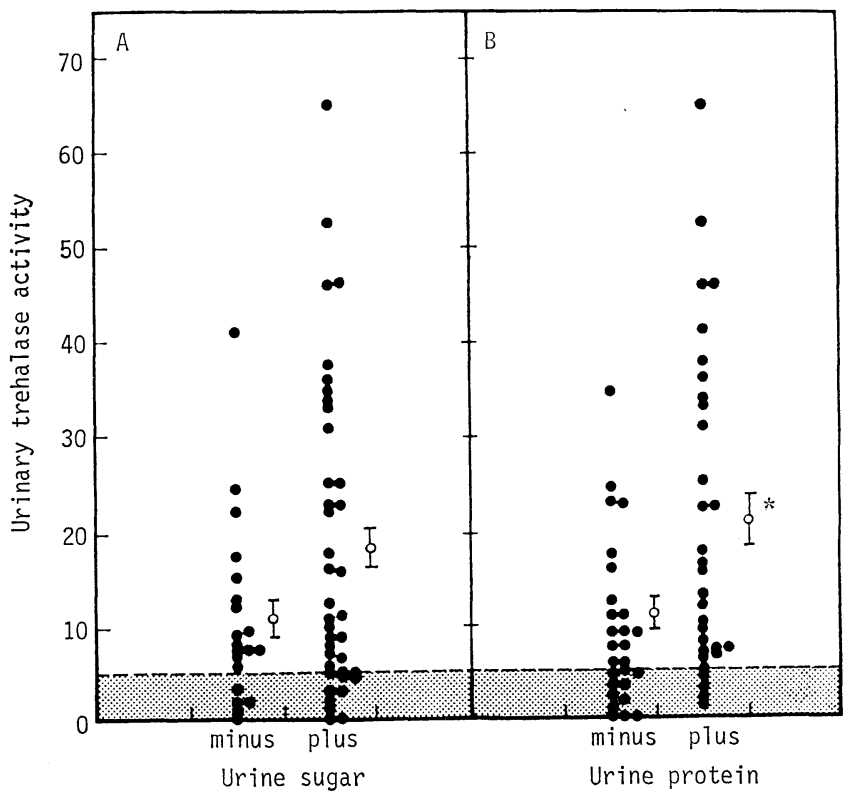

Fig. 2. Urinary trehalase activity of diabetics with glucosuria (A) or with proteinuria (B). Urine specimens were collected from 58 patients (mean age, 49 years; range 35-71 years). Significant difference: ${ }^{*} p<0.05$.

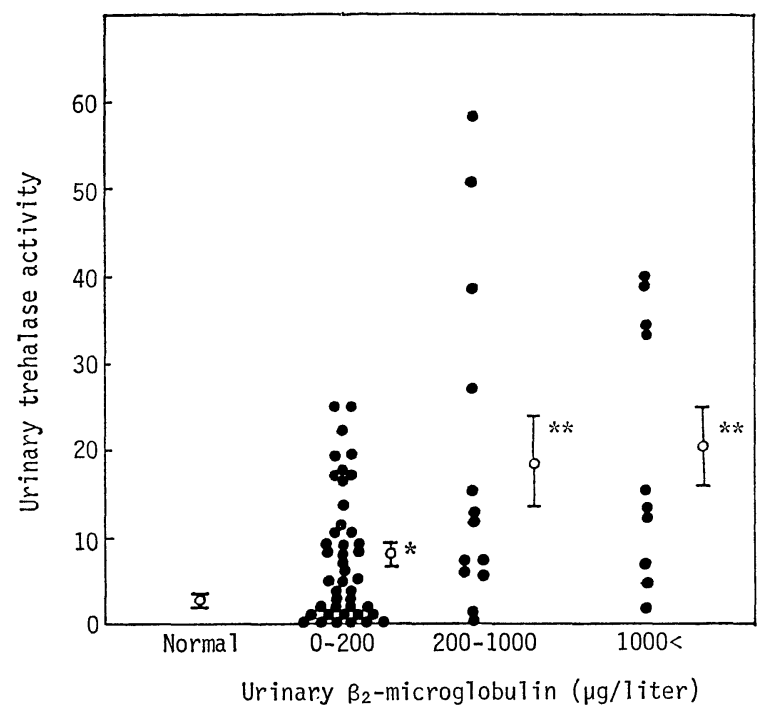

Fig. 3. Correlation between urinary trehalase activity and urinary $\beta_{2}$-microglobulin. Urine specimens were collected from 56 patients (mean age, 58 years; range 33-78 years). Significant difference: ${ }^{*} p<0.05 ; * * p<0.01$.

Vol. 3, No. 2, 1987 


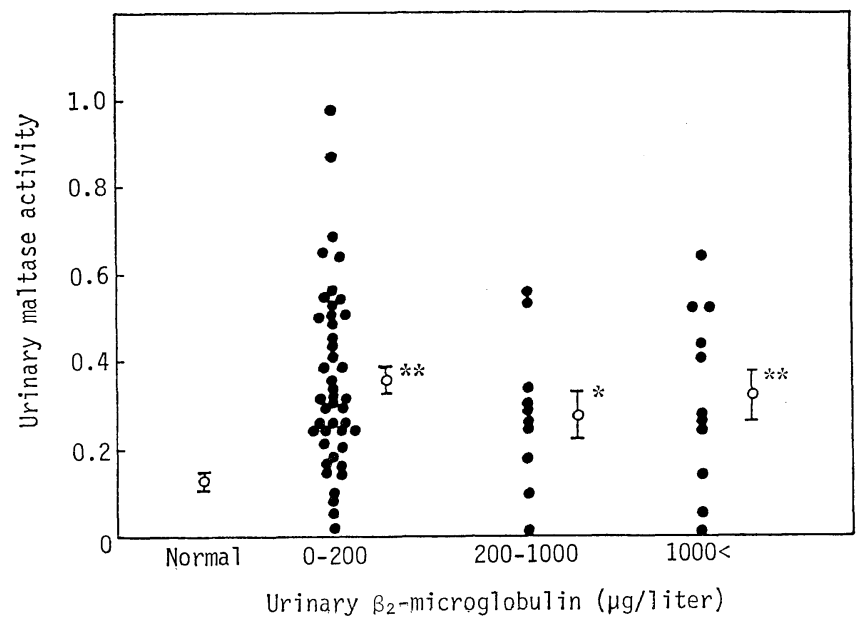

Fig. 4. Relationship between urinary maltase activity and urinary $\beta_{2}$-microglobulin. Urine specimens were collected from 66 patients (mean age, 59 years; range 30-77 years). Significant difference: ${ }^{*} p<0.05 ; * * p<0.01$.

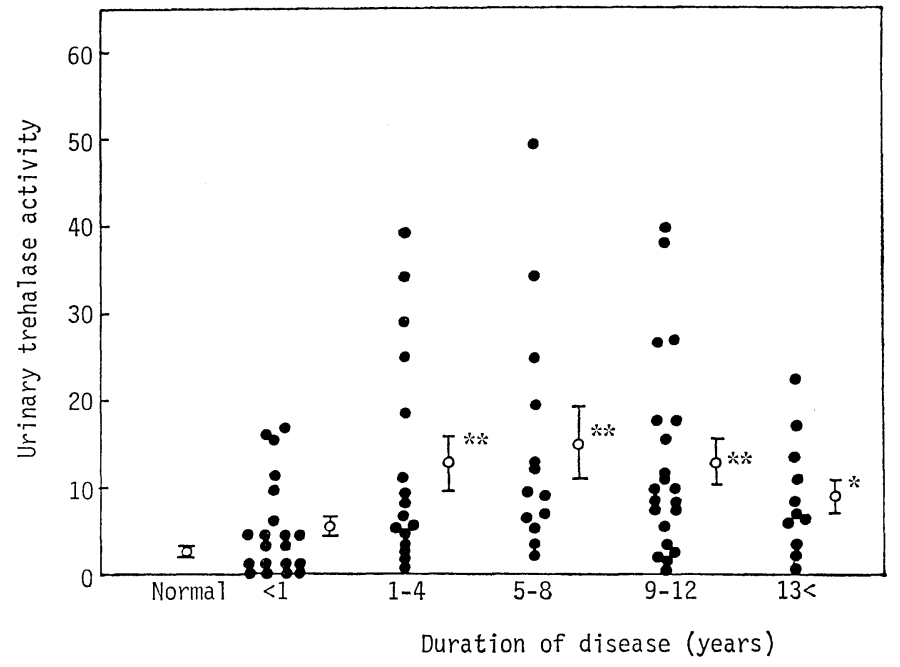

Fig. 5. Correlation between urinary trehalase activity and duration of diabetes mellitus. Urine specimens were collected from 81 patients (mean age, 57 years; range 33-76 years). Significant difference: $* p<0.05 ; * * p<0.01$. 


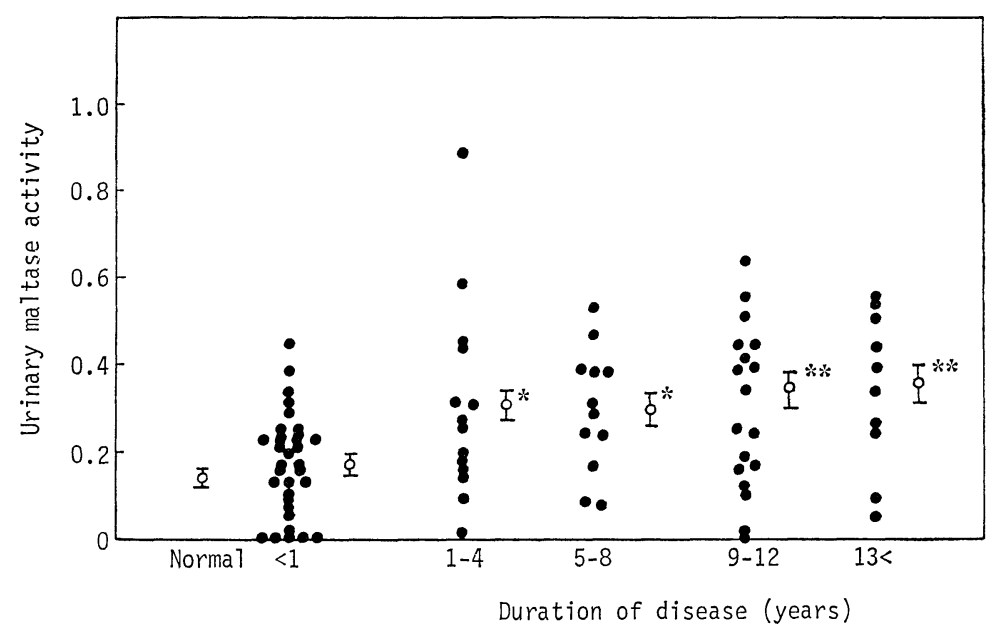

Fig. 6. Relationship between urinary maltase activity and duration of diabetes mellitus. Number of cases; 87 (mean age, 56 years; range 30-78 years). Significant difference: $* p<0.05 ; * * p<0.01$.

trehalase activity, but it was still significantly higher than that in the healthy individuals. In the case of urinary maltase activity (Fig. 6), the activity in diabetics with a duration of less than one year was not observed to be significantly different from the level in healthy individuals. Patients with a longer history of the disease showed significantly high urinary maltase activity as compared with the healthy normals.

\section{DISCUSSION}

Proteinuria is one clinical sign of nephropathy. Thus, it is noteworthy that urinary trehalase activity was elevated in the case of diabetics displaying neither proteinuria nor glucosuria (Fig. 2), even though the activity in those without proteinuria was lower $(p<0.05)$ than that in those with it. Parving et al. [3] reported that urinary $\beta_{2}$-microglobulin was elevated in patients with diabetes mellitus. As can be seen in Fig. 3, urinary trehalase activity was high at stages of the disease during which $\beta_{2}$-microglobulin was still at a low level $(0-200 \mu \mathrm{g} /$ liter $)$. Generally, it is thought that functional changes can be demonstrated in the disease after the development of morphological changes. Excretion of $\beta_{2}$-microglobulin is caused by failure of the tubular reabsorption mechanism [5], a functional failure. Renal trehalase is localized in the tubular brush borders [12-15], and urinary trehalase has the same antigenicity as the renal one $[10,11]$. Thus, the excretion of urinary trehalase is probably caused by damage to tubular brush borders, which appears as morphological changes $[10,11,17,18,25]$. Elevation of urinary trehalase was observed in patients suffering from Itai-itai disease and in inhabitants of a cadmium-polluted area (Jinzu River basin in Japan) [17, 18]. Furthermore, in the 
case of normal pregnancy, urinary trehalase activity was elevated significantly at the first trimester, and elevated further at the third trimester [20]. However, the elevated activity seen during pregnancy was completely restored to the normal level by one month after delivery [20]. From these results, it is inferred that the elevation of urinary trehalase seen in diabetes mellitus is caused by damage to renal tubules.

The urinary trehalase activity in patients with short duration of disease was higher than that in diabetics with long-term disease (Fig. 5). Patients with Itai-itai disease, who show severe tubular dysfunction, have low urinary trehalase activity [18]. Therefore, low urinary trehalase activity in disease of long duration (more than 13 years) might be due to the severe damage to tubular brush borders. That is, a gradual loss of trehalase from the tubules could be occurring during the long duration of disease.

Every brush border enzyme examined showed similar behavior in urine $(\mathrm{Fu}-$ kui et al., personal communication). After centrifugation of the urine, much of the enzyme activities (about $70 \%$ ) were recovered in the particulate fraction, indicating urinary excretion of brush borders. Brush border enzymes except trehalase have a wide distribution in the organ and broad substrate specificity [26-29]. Generally, it is thought that an indicator (a marker enzyme) should have a specific localization and a narrow substrate specificity. Trehalase has a specific localization and a extremely narrow substrate specificity [12-15]. Therefore we propose urinary trehalase to be a good indicator of renal tubular damage.

This work was partially supported by the Ishida Foundation. The authors express their thanks to the members of the expert clinical team in the 3rd Department of Internal Medicine, Nagoya University School of Medicine, for their helpful discussion. The excellent technical assistance of Mr. Takashi Sugita is gratefully acknowledged.

\section{REFERENCES}

1. Viberti, G.C. (1979): Early functional and morphological changes in diabetic nephropathy. Clin. Nephrol., 12, 47-53.

2. Morgensen, C.E. (1976): Renal function changes in diabetes. Diabetes, 25, 872-879.

3. Parving, H.H., Noer, I., and Deckert, F. (1976): The effect of metabolic regulation on microvascular permeability to small and large molecules in short-term diabetes. Diabetologia, 12, 161-166.

4. Peterson, P.A., Evrin, P.-E., and Berggard, I. (1969): Differentiation of glomerular, tubular and normal proteinuria: determinations of urinary excretion of $\beta_{2}$-microglobulin, and total protein. J. Clin. Invest., 48, 1189-1198.

5. Flynn, F.V., and Platt, H.S. (1968): Origin of the proteins excreted in tubular proteinuria. Clin. Chim. Acta, 21, 377-399.

6. Schreiner, G.E., and Maher, J.F. (1965): Toxic nephropathy. Am. J. Med., 38, 409-415.

7. Ellis, B.G., Price, R.G., and Tophan, F.C. (1973): The effect of tubular damage by mercuric chloride on kidney function and some urinary enzymes in the dog. Chem. Biol. Interact., 7, 101-112.

8. Dierikx, P.J. (1981): Urinary gamma-glutamyl transferase as an indicator of acute nephrotoxicity in rats. Arch. Toxicol., 47, 209-215. 
9. Stroo, W.E., and Hook, J.B. (1977): Enzymes of renal origin in urine as indicators of nephrotoxicity. Toxicol. Appl. Pharmacol., 39, 423-435.

10. Nakano, M., and Itoh, G. (1983): Elevation of urinary trehalase in mercuric chloride-induced nephrotoxic rabbits: urinary trehalase as a specific indicator of renal brush border damage. Chem. Biol. Interact., 45, 179-189.

11. Nishimura, N., Ohshima, H., and Nakano, M. (1986): Urinary trehalase as an early indicator of cadmium-induced renal tubular damage in rabbit. Arch. Toxicol., 59, 255-260.

12. Berger, S.J., and Sacktor, B. (1970): Isolation and biochemical characterization of brush borders from rabbit kidney. J. Cell Biol., 47, 637-645.

13. Sacktor, B. (1968): Trehalase and the transport of glucose in the mammalian kidney and intestine. Proc. Natl. Acad. Sci. US.A., 60, 1007-1014.

14. Sacktor, B. (1977): The brush borders of the renal proximal tubule and the intestinal mucosa, in Mammalian Cell Membranes, ed. by Jamieson, G.A., and Robinson, D.M., Butterworth, London, Vol. 4, pp. 221-254.

15. Nakano, M. (1982): Localization of renal and intestinal trehalase with immunofluorescenceand enzyme-labeled antibody techniques. J. Histochem. Cytochem., 30, 1243-1248.

16. Nakano, M. (1986): Intestinal and renal brush border membrane trehalase in mammals. Maku (Membrane), 11, 326-333 (in Japanese).

17. Nakano, M., Aoshima, M., Kato, T., Teranishi, H., and Kasuya, M. (1986): Urinary trehalase activity and brush border damages of inhabitants in cadmium polluted area (The Jinzu River basin). Toxicol. Lett., 34, 159-166.

18. Nakano, M., Aoshima, K., Katoh, T., Teranishi, H., and Kasuya, M. (1987): Elevation of urinary trehalase activity in patients of Itai-itai disease. Arch. Toxicol., 60, 300-303.

19. Shinoda, S., Yuri, K., and Nakagawa, S. (1977): Present status of Itai-itai disease: clinical findings by internal medicine. Kankyo Hoken Report, No. 41, 44-52 (in Japanese).

20. Higuchi, K., Asai, M., Suzuki, M., Noguchi, M., Ishihara, M., and Nakano, M. (1986): Urinary trehalase activity in normal pregnancy: on tubular dysfunction. Acta Obstet. Gynaecol. Jpn., 38, 2045-2049.

21. Nakano, M., Sumi, Y., and Miyakawa, M. (1977): Purification and properties of trehalase from rat intestinal mucosa cells. J. Biochem., 81, 1041-1049.

22. Nakano, M. (1982): Effect of inorganic anions on the inhibition of trehalase activity by mercuric chloride. Biochem. Biophys. Acta, 707, 115-120.

23. Dahlqvist, A. (1968): Assay of intestinal disaccharidase. Anal. Biochem., 22, 99-107.

24. Takagi, K., Itoh, Y., Enomoto, Y., Koyamaishi, Y., Maeda, K., and Kawai, T. (1980): A comparative study of serum $\alpha_{1}$-microglobulin and $\beta_{2}$-microglobulin levels in cancerous and other diseases. Clin. Chim. Acta, 108, 277-283.

25. Nakano, M. (1986): Clinical role of urinary trehalase in proximal tubular damages. Seikagaku, 58, 330-334 (in Japanese).

26. Rosenfeld, E.L. (1964): Animal tissue $\gamma$-amylase and its role in the metabolism of glycogen, in Control of Glycogen Metabolism, ed. by Whelan, W.J., J \& A Churchill, London, pp. 176-192.

27. Kaplan, M.M. (1972): Alkaline phosphatase. Gastroenterology, 62, 452-468.

23. Maeda, B.W., and Rasalki, S.B. (1964): Localization of leucine aminopeptidase isozymes. J. Clin. Pathol., 17, 61-63.

29. Goldbarg, J.A., Friedman, O.M., Pineda, E.P., Smith, E.E., Chatterji, R., Stein, E.H., and Rutenburg, A.M. (1960): The colorimetric determination of $\gamma$-glutamyl transpeptidase with a synthetic substrate. Arch. Biochem. Biophys., 91, 61-70. 